\title{
जithore ज्ञजि
}

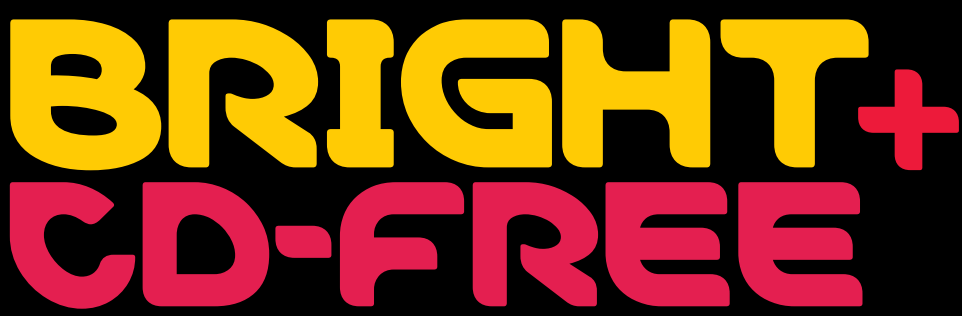

Quantum dots exhibit excellent photoluminescence and electroluminescence properties such as narrow emission bandwidth and high brightness.

\section{Choose cadmium-free quantum} dots for applications where toxicity is a concern.

\section{Cd-free Quantum Dots find applications in:}

- LEDs

- Displays

- Solid-state lighting

- Photovoltaics

- Transistors

To find out more, visit

SigmaAldrich.com/cd-freeqd
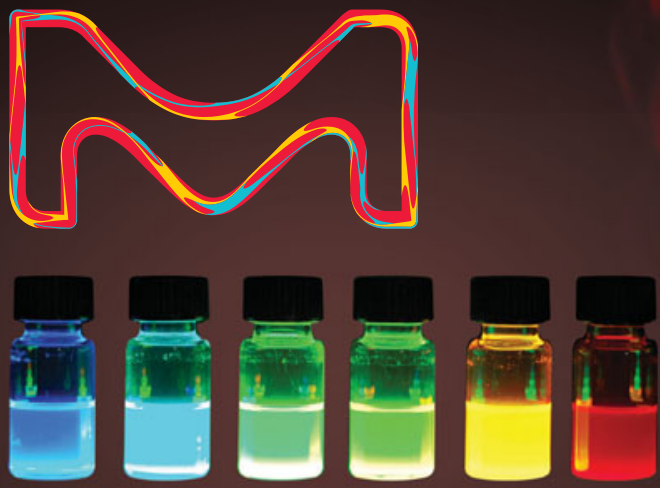

(C) 2018 Merck KGaA, Darmstadt, Germany and/or its affiliates. All Rights Reserved. MilliporeSigma and the Vibrant $M$ are trademarks
Germany or its affiliates.

2018 - $12263 \quad 05 / 2018$

\section{(1)}


THE ADVANCED MATERIALS MANUFACTURER @

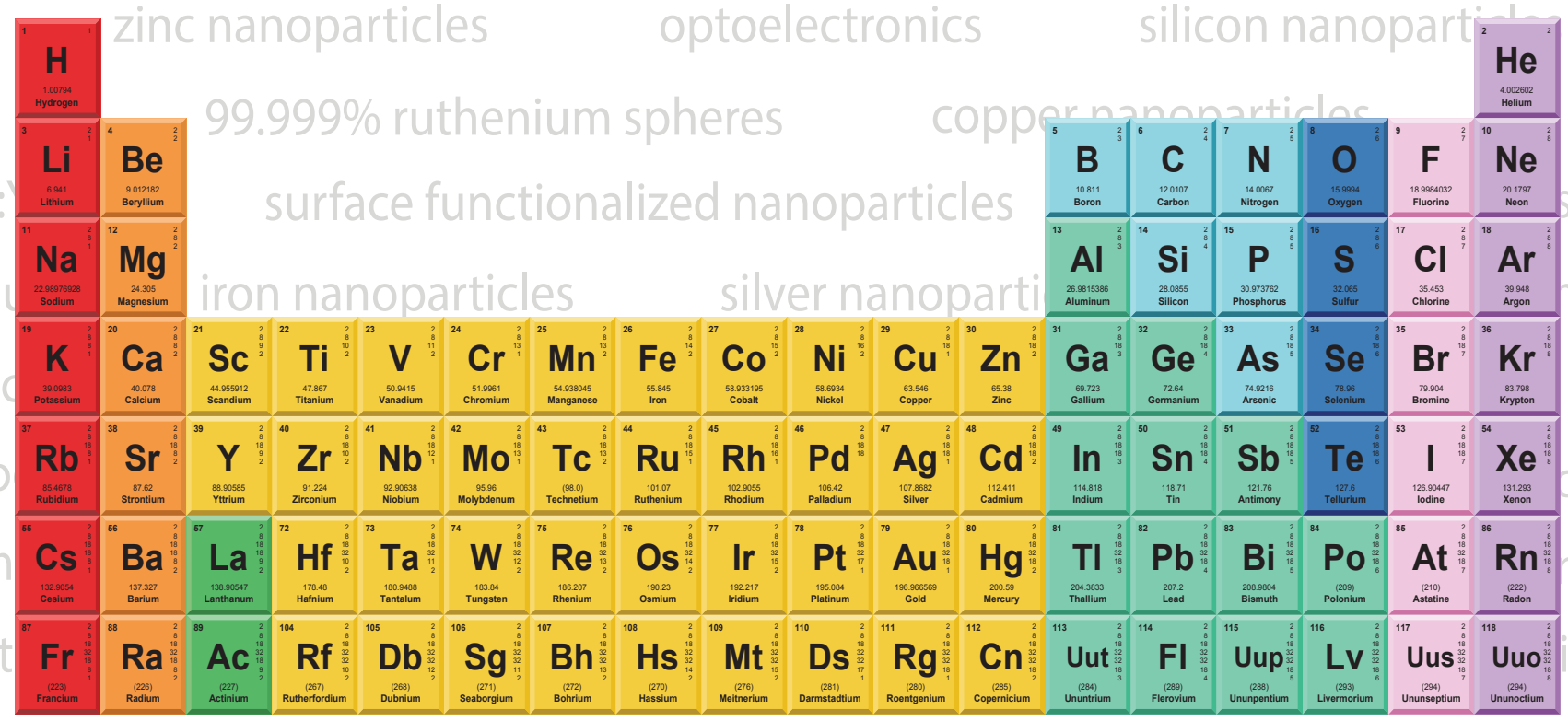

\begin{tabular}{|c|c|c|c|c|c|c|c|c|c|c|c|c|c|c|}
\hline & 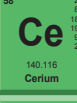 & 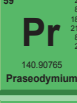 & 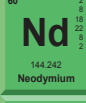 & $\mathrm{Pm}$ & 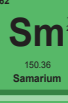 & $\begin{array}{c}\text { Eu } \\
\text { eusume } \\
\text { encomom }\end{array}$ & 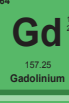 & 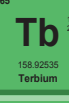 & 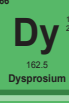 & 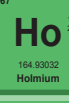 & 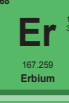 & 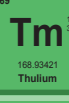 & 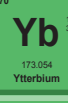 & $\underline{\mathrm{Lu}}$ \\
\hline & Th & 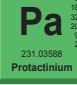 & 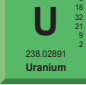 & $\mathrm{Np}$ & 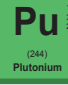 & $\mathrm{Am}$ & $\mathrm{Cm}$ & $\begin{array}{c}\text { Bk } \\
\text { Bentan } \\
\text { sentum }\end{array}$ & Cf & 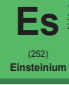 & 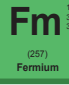 & 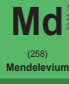 & 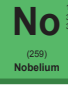 & 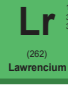 \\
\hline
\end{tabular}

\section{single crystal silicon}

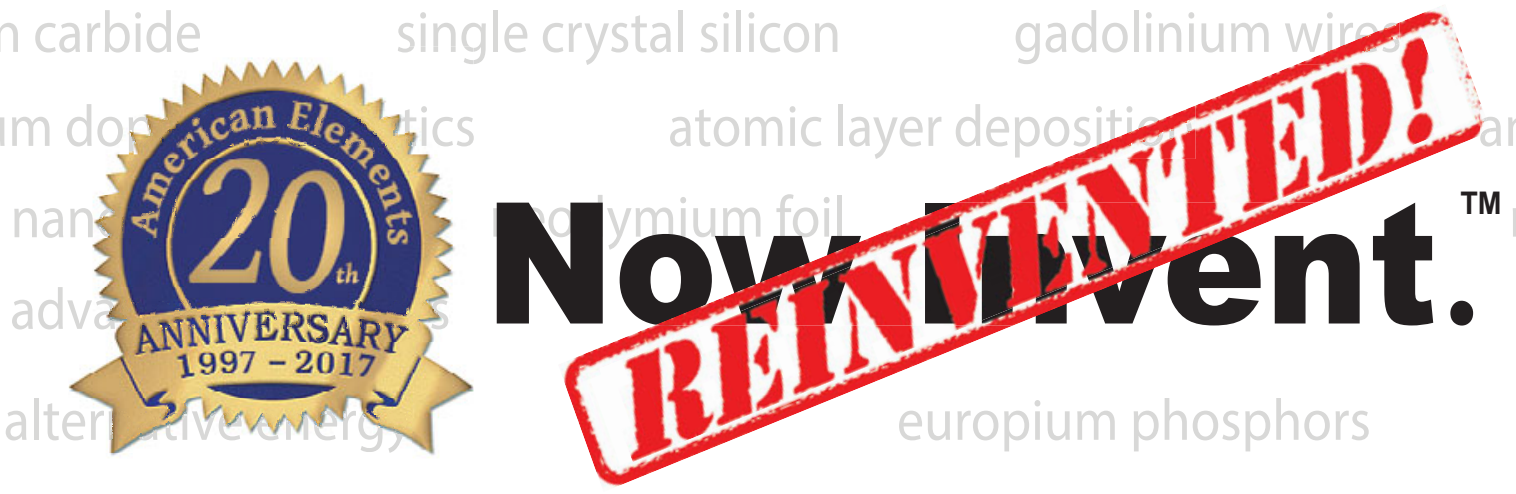

nano gels

\section{Experience the Next Generation of Material Science Catalogs}

As one of the world's first and largest manufacturers and distributors of nanoparticles \& nanotubes, American Elements' re-launch of its 20 year old Catalog is worth noting. In it you will find essentially every nanoscale metal \& chemical that nature and current technology allow. In fact quite a few materials have no known application and have yet to be fully explored. 